\title{
Percutaneous closure of iatrogenic femoral pseudoaneurysms with thrombin injection
}

\author{
Ahmet Karabulut \\ Department of Cardiology, Aclbadem University School of Medicine, Acıbadem Atakent Hospital, Istanbul, Turkey \\ a Acıbadem Atakent Hospital Department of Cardiology. Halkah Merkez Mah. Turgut Özal Bulvan, No:16, 34303 Kucukcekmece, Istanbul, Turkey.
}

\section{A R T I C L E I N F O}

\section{Article history:}

Received 9 June 2017

Received in revised form 14 July 2017

Accepted 17 July 2017

Available online 20 July 2017

\section{Keywords:}

Pseudoaneurysm

Femoral artery

Complication

Thrombin

\begin{abstract}
A B S T R A C T
Iatrogenic femoral artery pseudoaneurysm (IFP) is a tedious complication of percutanous coronary and peripheral interventions which prolong the in-hospital stay. It's overall incidence may increases to $8 \%$ in the therapeutic complex procedures. Surgical correction is a traditional approach which is still preferred as a first resort in the many cardiovascular centers in the Turkey. Herein, we aimed to demonstrate the feasibility of percutaneous closure of IFP with thrombin injection.

(c) 2017 The Society of Cardiovascular Academy. Production and hosting by Elsevier B.V. All rights reserved. This is an open access article under the CC BY-NC-ND license (http://creativecommons.org/licenses/by-nc-nd/4.0/).
\end{abstract}

\section{Introduction}

Iatrogenic femoral artery pseudoaneurysm (IFP) is a bind complication of percutanous coronary and peripheral interventions which would prolong the in-hospital stay. It is not uncommon condition and it's incidence was reported as $2,3 \%$ in the large cohort from Turkey. ${ }^{1}$ It's overall incidence may increases to $8 \%$ in the therapeutic complex procedures. ${ }^{2}$ Surgical correction is a traditional approach which is still preferred as a first resort in the many cardiovascular centers in the Turkey. Herein, we aimed to demostrate the feasibility of percutaneous closure of IFP with thrombin injection.

\section{Case report}

A 68 year-old male patient admitted to hospital with a complaints of groin pain and ecchymosis in the right thigh. On medical background, angioplasty and stent performed to left superficial femoral artery 5 days ago via right femoral route using $8 \mathrm{~F}$ introducer sheath. Doppler ultrasonography revealed $2 * 10 \mathrm{~cm}$ femoral pseudoaneurysm formation with a relatively narrow neck (Fig. 1). After initial evaluation, ultrasound guided manual compression was performed for $60 \mathrm{~min}$. However, flow in the pseudoaneurysm was persisted. After that, $2 \mathrm{ml}-$ 1000 units of thrombin (Tisseel lyo -Baxter) was injected into aneurysmal sac slowly (Fig. 2). Control Doppler ultrasonography showed cessation of diverted flow inside the pseudoaneurysm (Fig. 2). One week

E-mail address: ahmet.karabulut@acibadem.edu.tr. Peer review under responsibility of The Society of Cardiovascular Academy. control also showed complete embolisation of pseudoaneurysm with patent superficial femoral artery (Fig. 3).

\section{Discussion}

Pseudoaneurysms are one of the most major complications at the puncture site after catheterization percutaneous interventions. It is more common in elderly and women and it is associated with obesity, high dose antiplatelet regimen and prolonged complex vascular interventions. ${ }^{1}$ Basic therapuetic approach was defined as ultrasoundguided manual compression. Success rate was near to $50 \%$ and closure rate is more prominent in the pseudoaneurysms smaller than $20 \mathrm{~mm} .^{3}$ Ultrasound-guided manual compression is more effective in the patients who are not in anti-coagulative treatment, but may require prolonged compression and cause pain and discomfort. Ultrasoundguided percutaneous thrombin injection is going to be gold standard for IFP with clearly definable neck anatomy. ${ }^{2-4}$ In addition, dual antiplatelet therapy did not reverse the thrombin affect and size of the pseudoaneurysm is not limited factor. However, IFP without definive neck, IFP directly adjacent to vessels and IFP with concomitant arteriovenous fistula are not appropriate candidate for thrombin injection. ${ }^{3}$ Amount of thrombin injection may vary according to size of pseudoaneurysm and operator preference. It was reported that 2001000 units of thrombin might be enough to close pseudoaneursymal sac. ${ }^{5}$ Gentle and precise injection of the trombin is crucial since, leakage of tiny amount of thrombin may lead to thrombosis of main vessel and it can trigger acute limb ischemia. ${ }^{6}$ Injection of small incremental doses of thrombin may descrease the complication rate. In our case we injected 


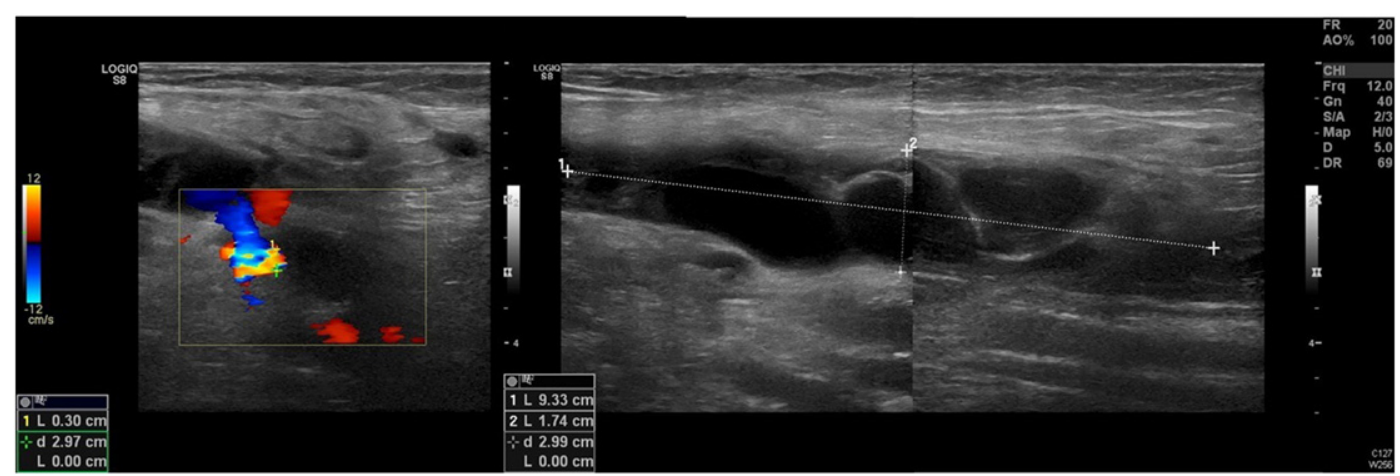

Fig. 1. Doppler ultrasonograpy show the pseudoaneurysm with definitive neck and hematoma formation.

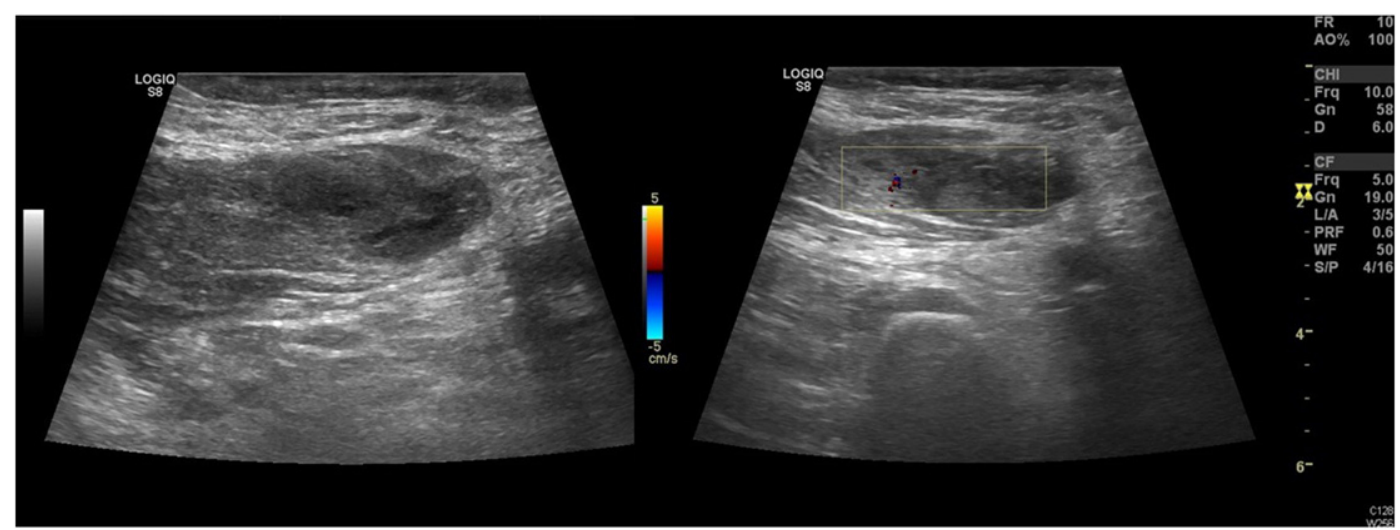

Fig. 2. Injection of thrombin solution to pseudoaneursymal sac.

relatively higher dose of thrombin (1000 units) without any complication and flow in the pseudoaneursymal sac was completely obliterated.

Graft stent deployment could be alternative therapy in unfavorable anatomic situation for thrombin injection. ${ }^{7}$ Surgical correction should be last resort in the treatment of IFP, and it should be preferred in the setting of imminent rupture, massive hematoma and skin necrosis.

\section{Conclusion}

Iatrogenic femoral artery pseudoaneurysm will continue to become a major vascular complication parallel to increment in the percutaneous complex vascular intervention. Ultrasound guided thrombin injection is safe and effective in the IFP with definitive neck anatomy. Habitual

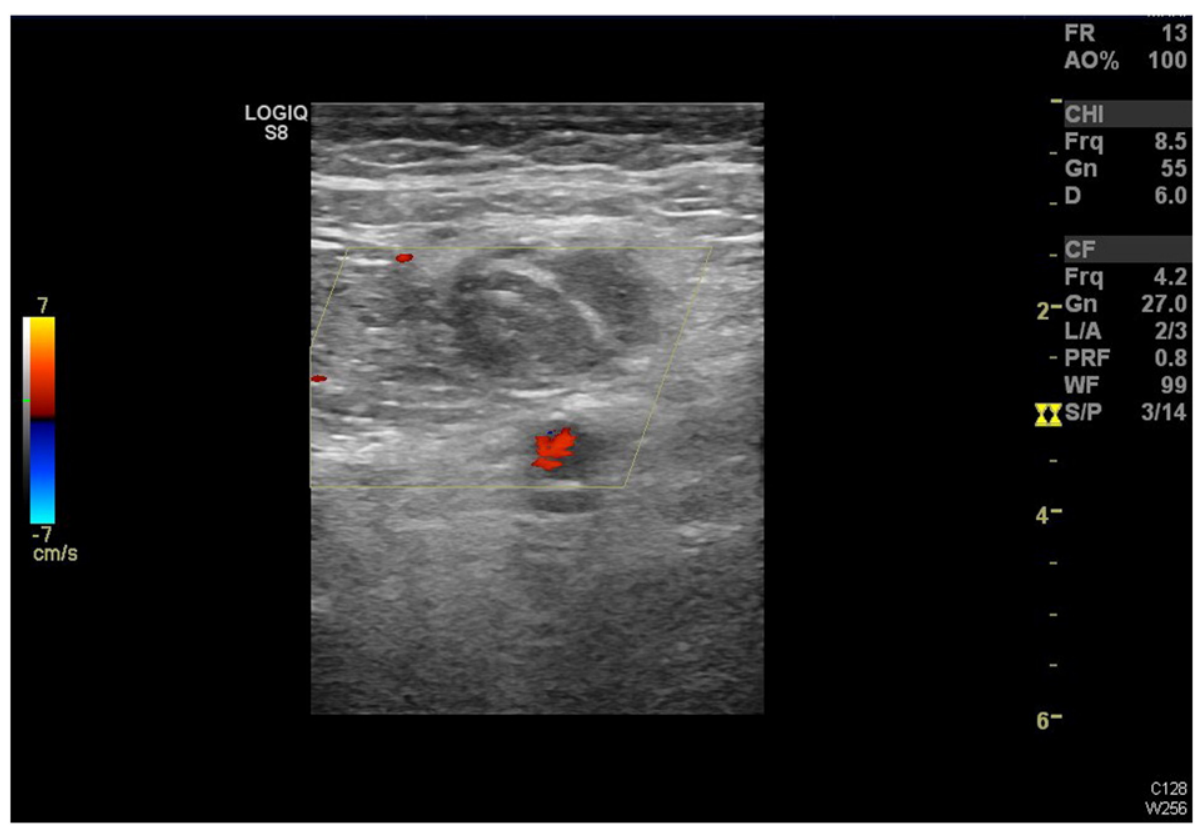

Fig. 3. Doppler ultrasonography show the complete obliteration of the flow within the pseudoaneurysm. 
traditonal surgical approach should be last resort in the treatment of IFP which is still not applicable in the current practice of our country.

\section{Acknowledgements}

The authors did not report conflict of interest regarding this work. This work was not supported by any company.

\section{References}

1. Ayhan E, Isik T, Uyarel H, et al. Femoral pseudoaneurysm in patients undergoing primary percutaneous coronary intervention for ST-elevation myocardial infarction: incidence, clinical course and risk factors. Int Angiol 2012 Dec;31(6):579-585.

2. Chen DH, Sammel AM, Jain P, Jepson NS. Cardiologist operated ultrasound guided thrombin injection as a safe and efficacious first line treatment for iatrogenic femoral artery pseudoaneurysms. Heart Lung Circ 2015 Feb;24(2):165-172.
3. Dzijan-Horn M, Langwieser N, Groha P, et al. Safety and efficacy of a potential treatment algorithm by using manual compression repair and ultrasound-guided thrombin injection for the management of iatrogenic femoral arterypseudoaneurysm in a large patient cohort. Circ Cardiovasc Interv 2014 Apr;7(2):207-215.

4. Kuma S, Morisaki K, Kodama A, et al. Ultrasound-guided percutaneous thrombin injection for post-catheterization pseudoaneurysm. Circ J 2015 Mar 20http: //dx.doi.org/10.1253/circj.CJ-14-1119.

5. Mishra A, Rao A, Pimpalwar Y. Ultrasound guided percutaneous injection of thrombin: effective technique for treatment of iatrogenic femoral pseudoaneurysms. J Clin Diagn Res 2017 Apr;11(4):TC04-TC06.

6. Yalcin MU, Gurses KM, Kocyigit D, Yorgun H, Sahiner ML. Expect the unexpected: acute and subacute coronary stent thrombosis following percutaneousthrombin injection for treatment of femoral pseudoaneurysm. Can J Cardiol 2014;30(12):1732.

7. Kufner S, Cassese S, Groha P, et al. Covered stents for endovascular repair of iatrogenic injuries of iliac and femoral arteries. Cardiovasc Revasc Med 2015http: //dx.doi.org/10.1016/j.carrev.2015.02.007. 